\title{
The investigation of absolute flow non-uniform velocity distributions influence at the centrifugal compressor axial radial impeller inlet using numerical calculation methods in ANSYS CFX
}

\author{
L.A. Rakhmanina ${ }^{1}$, A.V. Zuev ${ }^{1}$, A. Yu. Petrov ${ }^{1}$, A.A. Aksenov ${ }^{1, *}$ and Minh Hai Nguyen $^{2}$ \\ ${ }^{1}$ Peter the Great St. Petersburg Polytechnic University Federal State Autonomous Educational Institution of Higher Education, St. \\ Petersburg, Russia. \\ ${ }^{2}$ Petrovietnam Exploration Production Corporation, Ho Chi Minh City, Viet Nam
}

\begin{abstract}
Currently, methods of numerical modelling are widely used. They are especially widely used in the design of turbo compressors. For the specific task of designing new flowing parts of a centrifugal compressor, it is not recommended to deviate from the canonical design techniques, but it is preferable to supplement them with numerical methods. This article is devoted to the end two-element stage investigation of a centrifugal compressor with an axial radial impeller; the stage main dimensions were obtained using the method of V.F. Rice. In order to obtain the necessary pressure characteristics and determine the dependence for the absolute velocity non-uniform distribution at the inlet to the axial radial impeller, the flow path main dimensions were optimized using numerical calculation methods. The calculation was performed using the SST turbulence model using computational gas dynamics methods in the ANSYS CFX software environment. Based on the optimization results, five compressor designs and corresponding characteristics were obtained. The absolute velocity distribution nature at the inlet to the centrifugal compressor axial radial impeller for five flow path variants is investigated. Empirical dependences are obtained for the deviation of the absolute velocity at the inlet in the hub section axial radial impeller and the absolute velocity deviation at the shroud from the absolute velocity at the average diameter based on the results of a numerical experiment. Recommendations are made for further absolute velocity distributions investigating at the inlet to the compressor impeller.
\end{abstract}

\section{Introduction}

The gas industry is one of the leading fuel and energy complex sectors. Technical progress and the country national economy development pace depend on its condition. And this industry is one of the most important applications of centrifugal compressors [1,2,3,4 etc.]. Centrifugal compressors are used in gas production, storage, for its further transportation and preparation for it. Therefore, the machines efficiency has a big impact on the performance of this industry. Turbo compressors consume large amounts of energy. Therefore, to reduce financial costs, it is necessary to increase the efficiency of compressors, which means to create the optimal machine flow path shape. In connection with the growth of requirements [2] for modern centrifugal compressors, both in terms of required pressure and energy efficiency, the need for the production of highly efficient axial radial impellers is increasing. This article continues the designed stage investigation under various working conditions by numerical calculation methods, which was begun in [5].

The objectives of this work:
1. The designed centrifugal compressor two-element end stage optimization, in particular the axial radial impeller, its basic geometric parameters and the angles distribution of axial radial impeller blade installation at the inlet.

2. The absolute velocity distribution dependence at the inlet to the centrifugal compressor axial radial impeller based on the absolute velocity distribution obtained by numerical calculation methods in Ansys CFX.

\section{Methods}

As the main research method, a numerical experiment was used. To solve these problems, CFD modelling (Ansys software package) was used using recommendations for constructing, calculating and modeling centrifugal compressors $[2,6,7,8,9,10,11$, $21,22,23,24]$. Programs for calculating the quasithree-dimensional inviscid flow in the impellers blade lattices and the developed mathematical model for the

* Corresponding author: aksenovaax@mail.ru 


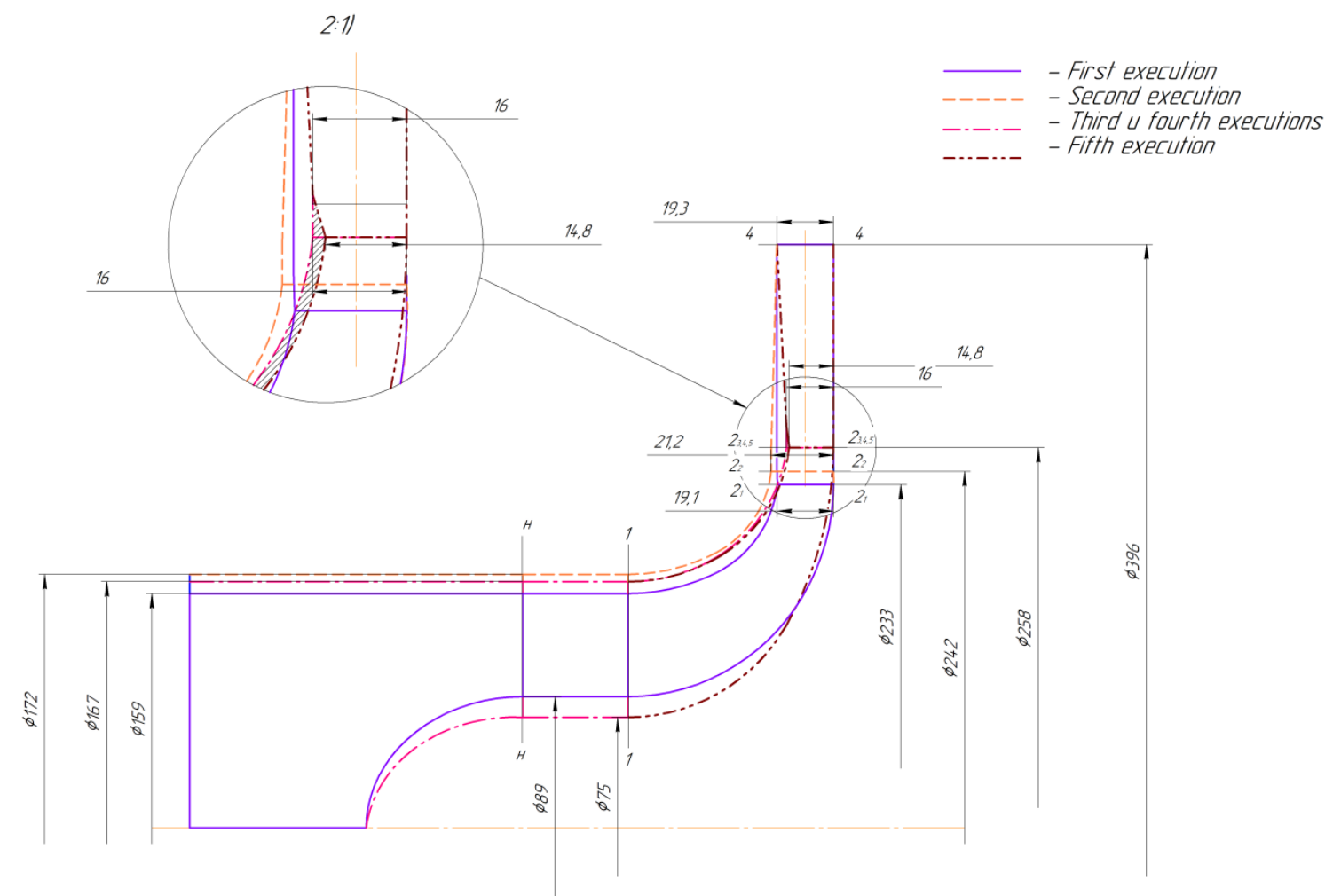

Fig. 1. The centrifugal compressor stage meridional section with control sections and changes in the flow path geometry, depending on optimization approaches (dimensions in $\mathrm{mm})$ in five execution $(\mathrm{H}-\mathrm{H}$ - axial pipe inlet section; 1 - 1 - section at the impeller front; $2_{1}-2_{1}$ - section behind the impeller, the first version; $2_{2}-2_{2}$ - section behind the impeller, the second version; $23,4,5-23,4,5$ - section behind the impeller, the third, fourth and fifth execution; $4-4$ - vaneless diffuser outlet section).

design and calculation of centrifugal compressors and compressor stages were used [12, 13, 14].

The object of research is a three-dimensional flow path model of a centrifugal compressor two-element stage. The basic stage geometric parameters are designed according to the method of V.F. Rice [4]. The investigated stage is of ending type. The stage design (Fig. 1.) includes an axial-radial impeller of a half-open type with dimensional blades and a vaneless diffuser. There is an axial nozzle with a stationary fairing at the inlet.

The stage was studied at a constant speed of rotation $n=20000 \mathrm{rev} / \mathrm{min}$ and various mass flow rates: $\bar{m}=50-$ $70 \mathrm{~kg} / \mathrm{sec}$. Values of estimated conditional flow coefficient are in the range of $0,077 \leq \Phi_{R} \leq 0,108$.

The working fluid is natural gas. Its composition is shown in table 1 , the mixture was calculated according to the BVR method [15] using additional modifications [16.17].

Table 1. - The gas mixture composition.

\begin{tabular}{|c|c|}
\hline Gas & Composition percentage \\
\hline Methane & 98,84 \\
\hline Ethane & 0,10 \\
\hline Propane & 0,03 \\
\hline N-Butane & 0,02 \\
\hline N-Pentane & 0,01 \\
\hline Nitrogen & 0,70 \\
\hline $\mathrm{CO}_{2}$ & 0,30 \\
\hline
\end{tabular}

Compressor parameters:

Inlet pressure: $\mathrm{P}_{\mathrm{i}}=6,1 \mathrm{MPa}$;

Outlet pressure: $\mathrm{P}_{\mathrm{o}}=7,7 \mathrm{MPa}$;

Inlet temperature: $\mathrm{T}_{\mathrm{i}}=303,15 \mathrm{~K}$.

The boundary conditions for the objective were adopted on the basis of existing recommendations for the problems of three-dimensional design of two-element stages with axial radial axis $[5,6,7,18,19,20]$. The boundary conditions were not changed during all the optimizations, except for mass flow, as indicated above.

Boundary conditions specified in ANSYS CFX:

Turbulence regime: Medium (Intensity=5\%);

Turbulence model: SST;

Fluid: Natural gas;

Heat Transfer: Total energy;

Rotation frequency, n, rev/min: $\mathrm{n}=20000 \mathrm{rev} / \mathrm{min}$;

Flow regime: Subsonic;

Total inlet temperature, $\mathrm{T}^{*}, \mathrm{~K}: \mathrm{T}^{*}=303,15 \mathrm{~K}$;

Total inlet pressure, $\mathrm{P}^{*}$, MPa: $\mathrm{P}^{*}=6,1 \mathrm{MPa}$;

Mass flow rate, $\overline{\mathrm{m}}$, kg/sec: $\overline{\mathrm{m}}=50-70 \mathrm{~kg} / \mathrm{sec}$.

\section{Results}

After the two-element end stage analytical design, it was decided to optimize the compressor flow path by numerical simulation using the Ansys CFX software package. During the first three approaches, the parameters of sections 1-1 and 2-2 were changed with a constant section 4-4: the impeller inlet diameter $D_{1}$, the 
hub diameter ratio $\bar{D}_{h}$, from the outlet impeller diameter $D_{2}$, the channel width at the impeller outlet $b_{2}$.

After the first calculation, in the second approach, the impeller inlet diameter, the from the outlet impeller, and the channel at the impeller outlet width were increased (Fig. 1). The hub diameter and the section 4-4 parameters remained unchanged. The vaneless diffuser walls became curved, but this did not give optimal results. On the contrary, the efficiency and pressure ratio decreased significantly in comparison with the first calculation (Fig. 2). And the flow at the impeller outlet lag angle increased (Fig. 3).

In the third approach have been reduced: the stub ratio, the impeller inlet diameter and the channel width at the impeller outlet, and the impeller outlet diameter was increased (Fig.1). Thus, the flow passage was considerably lengthened in comparison with the original version for further dimensionless diameter influence investigation at absolute velocity distribution picture at the wheel inlet. The third optimization approach results are adopted for the optimum (Fig.2 and Fig.3). Further approaches were carried out to account for the backlog at the wheel outlet angles influence and the blades angles on the absolute velocity distribution pattern in the section 1-1. Figure 2 presents the main relative efficiency for static parameters characteristics, where the efficiency of all approaches of optimization is given to the third approach efficiency in the current mode.

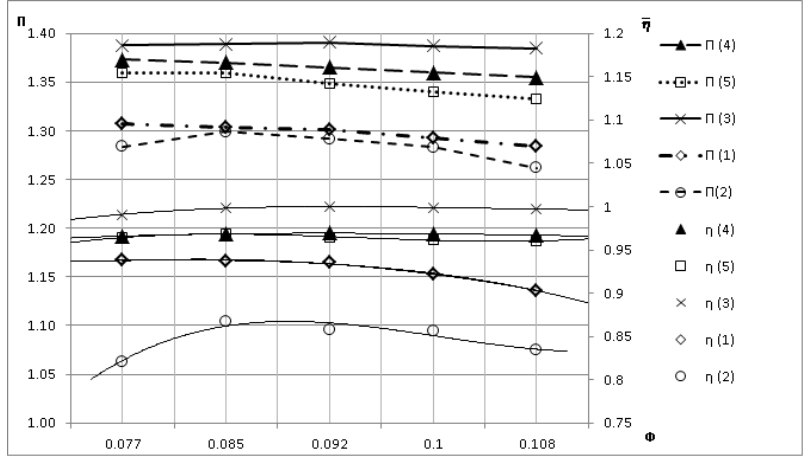

Fig. 2. The pressure ratio and relative efficiency for static parameters in section 4-4 for five optimization approaches.

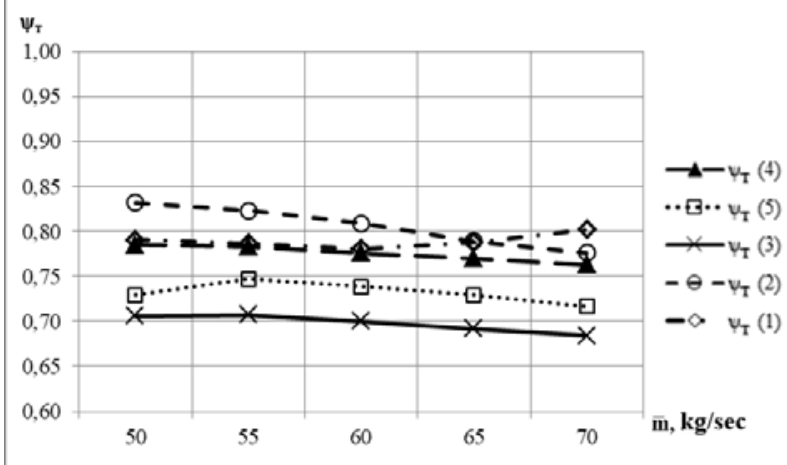

Fig. 3. The theoretical pressure coefficient $\psi \mathrm{T}$ on the mass flow rate dependence.

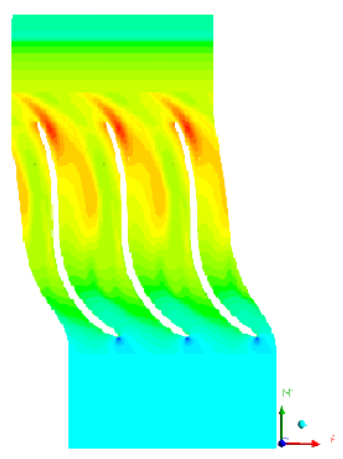

Execution 3

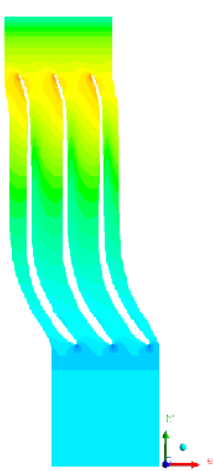

Execution 3

Shroud absolute velocity distribution

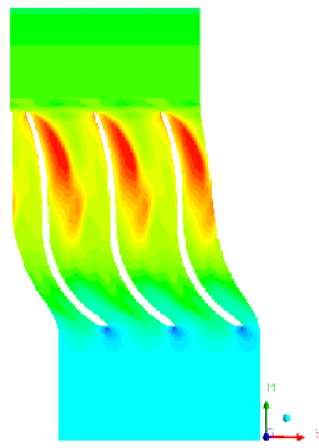

Execution 4

Hub absolute velocity distribution

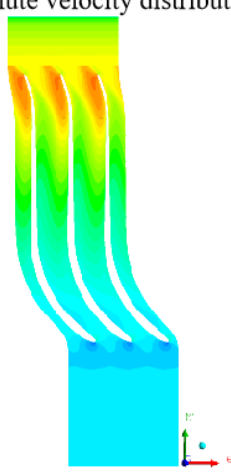

Execution 4

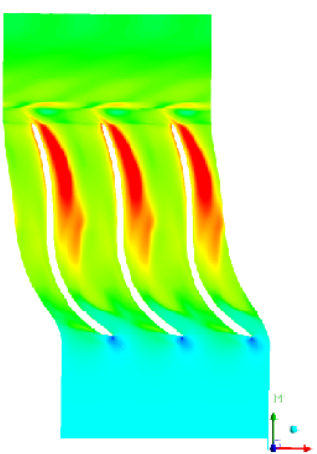

Execution 5

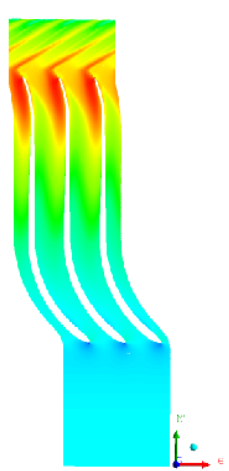

Execution 5

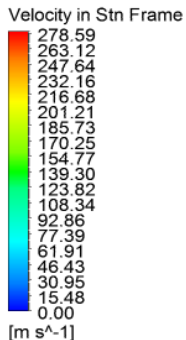

Fig. 4. The absolute velocity distribution in the hub and shroud sections for the third, fourth and fifth executions. 


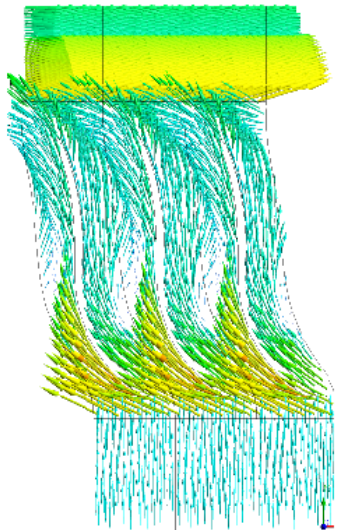

Execution 3

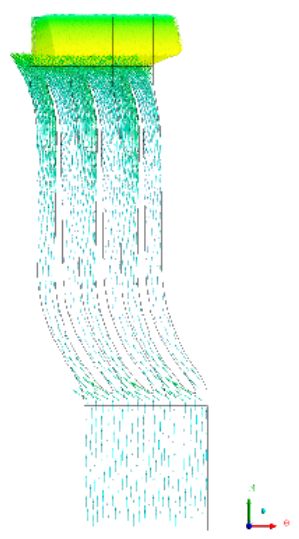

Execution 3

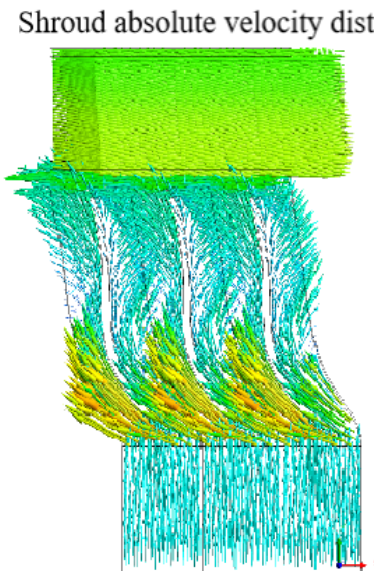

Execution 4

Hub relative velocity distribution

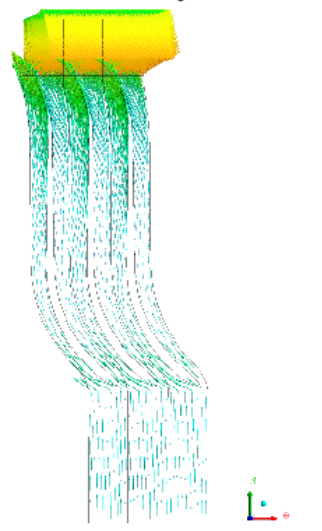

Execution 4

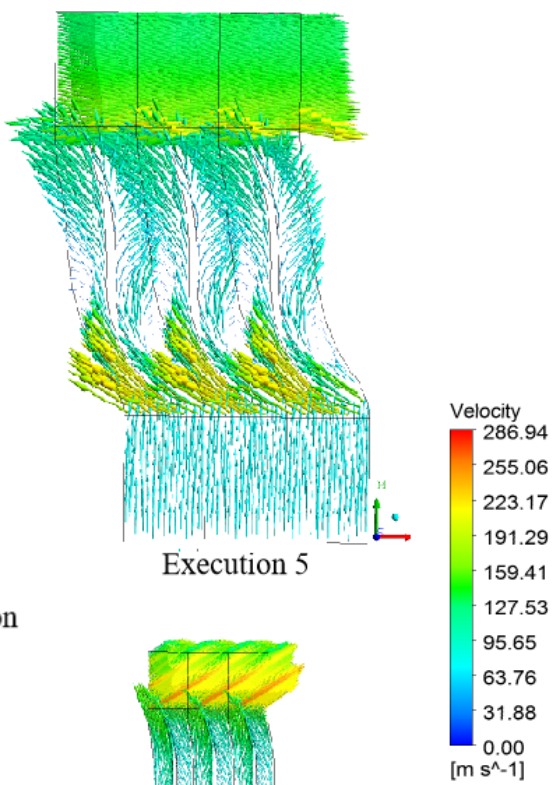

Execution 5

Fig. 5. The distribution of relative velocity in the hub and shroud sections for the third, fourth and fifth executions.

But in the third approach case, during optimization, shock flow is found around the blade at the inlet to the impeller (Fig. 4), therefore, in the fourth approach, it was decided to change the installation blade angles along the sections: $\beta_{b H}, \beta_{b A V}, \beta_{b S H}$, leaving all other geometric and gas-dynamic parameters unchanged. In the fourth optimization approach, we managed to improve the flow around the inlet, but at the outlet from the impeller there was a flow stall from the blade (Fig. 4. and Fig. 5).

In order to avoid flow stall at the axial radial impeller outlet in the fifth approach, it was decided to reduce the channel width in the section 2-2 $b_{2}$, and leave the channel width at the inlet to the vaneless diffuser unchanged. $b_{3}=$ const As a result, the flow around the impeller blades was significantly improved. But pressure characteristics expectedly worsened: the pressure ratio decreased significantly compared to the third approach. Efficiency, although it decreased, nevertheless, remained quite high (Fig. 2.).

Also, in the calculation, non-canonical velocities pictures is were obtained distributions at the inlet to the centrifugal compressor impeller according to numerical modeling. According to the results of numerical modelling, the absolute velocity at the inlet to the impeller varies over sections, increasing from the hub section to the shroud (Fig. 6). While in canonical techniques, the absolute velocity at the inlet to the impeller is considered constant. In this case, the calculated absolute velocity over the inlet to the impeller entire surface is equal to the absolute velocity at the average diameter. Table 2 shows the distribution of absolute velocity, relative velocity and absolute velocity expenditure component at various mass flow rates numerical values.

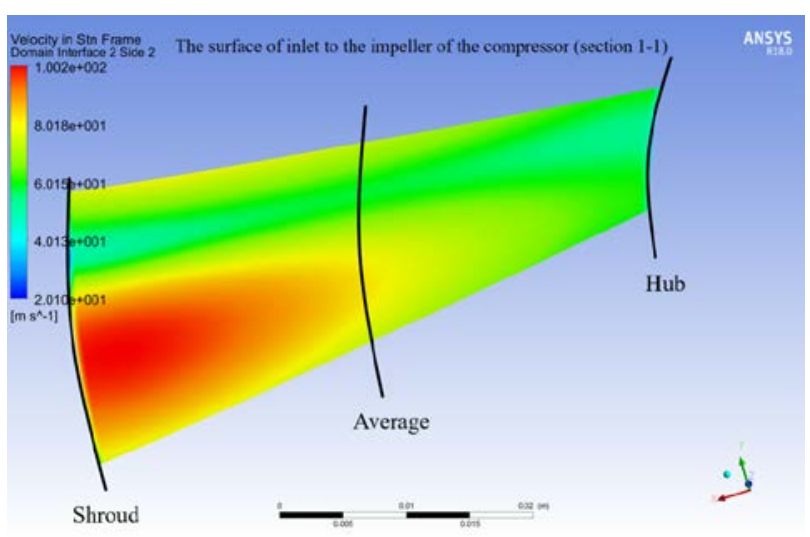

Fig. 6. The distribution of absolute velocity at the inlet to the impeller (section 1-1) after the fifth optimization approach. 
Table 2.Velocity distribution in section 1-1 after the fifth optimization approach.

\begin{tabular}{|c|c|c|c|}
\hline Diameter & $\begin{array}{l}\text { Relative velocity } \\
\text { W, m/sec }\end{array}$ & $\begin{array}{l}\text { Absolute velocity } \\
\text { C, m/sec }\end{array}$ & $\begin{array}{l}\text { Consumption component of velocity } \\
\mathrm{Cm}, \mathrm{m} / \mathrm{sec}\end{array}$ \\
\hline \multicolumn{4}{|c|}{ Mass flow rate $50 \mathrm{~kg} / \mathrm{sec}$} \\
\hline Hub & 98.305 & 54.278 & 54.087 \\
\hline Average & 141.52 & 65.708 & 64.963 \\
\hline Shroud & 182.806 & 70.37 & 69.691 \\
\hline \multicolumn{4}{|c|}{ Mass flow rate $55 \mathrm{~kg} / \mathrm{sec}$} \\
\hline Hub & 100.69 & 58.403 & 58.228 \\
\hline Average & 144.38 & 71.496 & 70.609 \\
\hline Shroud & 186.943 & 80.17 & 79.722 \\
\hline \multicolumn{4}{|c|}{ Mass flowrate $60 \mathrm{~kg} / \mathrm{sec}$} \\
\hline Hub & 103.957 & 63.784 & 63.628 \\
\hline Average & 147.788 & 77.993 & 77.105 \\
\hline Shroud & 190.555 & 88.14 & 87.808 \\
\hline \multicolumn{4}{|c|}{ Mass flowrate $65 \mathrm{~kg} / \mathrm{sec}$} \\
\hline Hub & 107.549 & 69.412 & 69.267 \\
\hline Average & 151.458 & 84.679 & 83.796 \\
\hline Shroud & 194.309 & 95.894 & 95.633 \\
\hline \multicolumn{4}{|c|}{ Mass flow rate $70 \mathrm{~kg} / \mathrm{sec}$} \\
\hline Hub & 111.454 & 75.25 & 75.11 \\
\hline Average & 155.397 & 91.491 & 90.609 \\
\hline Shroud & 198.269 & 103.605 & 103.387 \\
\hline
\end{tabular}

Based on numerical experiments, for this object of investigation, absolute velocity deviation power-law dependence at the extreme sections $\chi$ on the hub diameter to the impeller inlet diameter ratio was derived $D_{h} / D_{0}$ (Fig. 7).

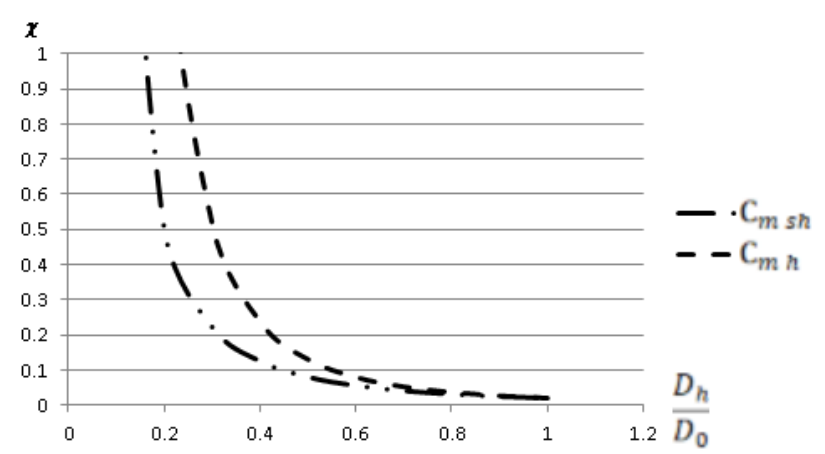

Fig. 7. The absolute velocity deviation on the blade hub and shroud diameter from the absolute velocity average value at different ratios $D_{h} / D_{0}$.

The absolute velocity deviation on the blade hub diameter from the absolute velocity on the average diameter:

$$
\chi_{\mathrm{h}}=0,02 \cdot\left(\frac{D_{0}}{D_{h}}\right)^{2} \cdot\left(\frac{D_{0}}{D_{h}}\right)^{D_{0}}
$$

The absolute velocity deviation on the blade shroud diameter from the absolute velocity on the average diameter:

$$
\chi_{\mathrm{sh}}=0,02 \cdot\left(\frac{D_{0}}{D_{h}}\right)^{2}
$$

The change in the velocity expendable component dependence in section 1-1 along the blades height using the correction coefficient $\chi$ :

$$
\begin{gathered}
C_{\mathrm{m} \mathrm{sh}}=\chi_{\mathrm{sh}} \cdot \frac{\overline{\mathrm{m}}}{\rho_{1} \cdot \mathrm{F}_{1}} \\
C_{\mathrm{m} \mathrm{h}}=\chi_{\mathrm{h}} \cdot \frac{\overline{\mathrm{m}}}{\rho_{1} \cdot \mathrm{F}_{1}} \\
C_{\mathrm{m} \mathrm{av}}=\frac{\overline{\mathrm{m}}}{\rho_{1} \cdot \mathrm{F}_{1}}
\end{gathered}
$$

These dependencies illustrate the heterogeneous absolute velocity distribution at the inlet to the impeller. They are necessary for profiling the input impeller blades edge at an angle $\beta_{b 1}$ along the blades height. Further, studies in this direction are ongoing; studies will be performed on other axial radial impellers at various optimal flow and pressure ratios.

\section{Conclusions}

Five approaches were applied in the work to optimize the designed single-stage centrifugal compressor flow path in the Ansys CFX software package in order to obtain the optimal stage efficiency. As a result of optimization, the necessary pressure characteristic was 
obtained, the stage efficiency was increased (Fig. 2, Fig. 3 ) and the flow around the blade apparatus was improved (Fig. 4, Fig. 5).

It is shown that the absolute velocity at the inlet to the compressor axial radial impeller blades from the hub to the shroud has an uneven distribution. The absolute velocity dependences deviation at the inlet to the impeller obtained in the work are derived on the investigation basis of one object and therefore require further studies on other axial radial impellers, including non-stationary modes. They also need to be verified by a real experiment. The obtained dependences (1) and (2) for determining the flow irregularity at the inlet to the axial-radial impeller can be applied in analytical methods for calculating the impellers when determining the inlet angle $\beta_{b 1}$ from the blades height.

\section{References}

1. Yun V.K. The use of advanced technologies to increase the economic efficiency of a centrifugal compressor. Gas industry №9, 2014, pp. 68-71.2.

2. Aksenov, A.A., Danilishin, A.M., Kozhukhov, Y.V., Simonov, A.M. Numerical simulation of gasdynamic characteristics of the semi-open 3D impellers of the two-element centrifugal compressors stages.(2018) AIP Conference Proceedings, 2007, article № 030025.DOI: 10.1063/1.5051886

3. Burdyugov S.I., EryshkinYu.P., Kasyanov S.V., Makarov A.A. Experience in commissioning of multi-stage pulp and paper mill with magnetic suspension. Compressor Technology №1, 2019, 33.

4. M. Inoue and N. A. Cumpsty, "Experimental study of centrifugal impeller discharge flow in vaneless and vaned diffusers," Journal of Engineering for Gas Turbines and Power, vol. 106, no. 2, p. 455, 1984 DOI: $10.1115 / 1.3239588$

5. M. V. Casey, P. Dalbert, and P. Roth, "The use of $3 \mathrm{D}$ viscous flow calculations in the design and analysis of industrial centrifugal compressors," Journal of Turbomachinery, vol. 114, no. 1, pp. 2737, 1992. DOI: 10.1115/1.2927995

6. Aksenov, A.A., Danilishin, A.M., Dubenko, A.M., Kozhukov, Y.V. Development of the virtual experimental bench on the basis of modernized research centrifugal compressor stage test unit with the 3D impeller.(2017) IOP Conference Series: Materials Science and Engineering, 232 (1), article № 012042. DOI: 10.1088/1757-899X/232/1/012042

7. Danilishin AM, KozhukhovYu.V., Development and evaluation of the effectiveness of the parametric model of the flow part of the axial radial impeller of a centrifugal compressor. Science Week SPbPU Materials of the scientific forum with international participation. Institute of Energy and Transport Systems. St. Petersburg, 2015, pp. 293-295.

8. Danilishin A., Kozhukhov Y., Yun V, Multiobjective optimization for impeller shroud contour, the width of vane diffuser and the number of blades of the centrifugal compressor stage based on the CFD calculation. IOP Conference Series Materials Science and Engineering 08/2015;Volume 90(1):012047. 899X/90/1/012046

9. GalerkinYu.B., KozhukhovYu.V., Danilyshin A.M. A comparative analysis of the results of calculating a viscous three-dimensional flow in the Ansys CFX 14.0 software package and a full-scale experiment for an intermediate-type centrifugal compressor stage taking into account leaks. // Science Week SPbSPU. The best reports: materials of a scientificpractical conference with international participation. - SPb .: Publishing house of the Polytechnic University, 2013. - 17-20.

10. Danilishin, A.M., Kozhukhov, Y.V., Neverov, V.V., Malev, K.G., Mironov, Y.R. The task of validation of gas-dynamic characteristics of a multistage centrifugal compressor for a natural gas booster compressor station. (2017) AIP Conference Proceedings, 1876, article № 020046. DOI: 10.1063/1.4998866

11. Danilishin, A.M., Kozhukhov, Y.V., Yun, V.K. Multi-objective optimization for impeller shroud contour, the width of vane diffuser and the number of blades of the centrifugal compressor stage based on the CFD calculation(2015). IOP Conference Series: Materials Science and Engineering, 90 (1), article № 012046.DOI: 10.1088/1757899X/90/1/012046

12. A.M. Simonov. Efficiency research and optimal design of high-pressure centrifugal compressor stages. P. 164 - 188. / Proceedings of the Scientific School of Compressor Engineering SPbSPU. Under the editorship of Professor Yu.B. Galerkin. - Publishing house SPbSPU, SPb, 2010 - 670 pp.

13. Salame S.I. Calculation of losses in centrifugal compressor stages with axially radial half-open impellers based on mathematical modeling: (05.04.06): Abstract of dissertation for the degree of candidate of technical sciences. Leningrad,1982.

14. Smagorinsky A.M. The methodology for determining the gas-dynamic, structural parameters and the efficiency of the axial-radial impellers of industrial centrifugal compressors: (05.04.06): Abstract of the dissertation for the degree of candidate of technical sciences. St. Petersburg, 2010

15. R. Z. Ríos-Mercado and C. Borraz-Sánchez, "Optimization problems in natural gas transportation systems: A state-of-the-art review," Applied Energy, vol. 147, pp. 536-555, 2015. DOI: 10.1016/j.apenergy.2015.03.017

16. Aksenov, A., Kozhukhov, Y., Sokolov, M., Simonov, A. Analysis and modernization of real gas thermodynamic calculation for turbocompressors and detander units. (2018) MATEC Web of Conferences, 245, article № 09005. DOI: 10.1051/matecconf/201824509005

17. Aksenov A.A., Sokolov M.I., Chernyshev M.S., Nazarenko N.A. Analysis and modernization of the program for thermodynamic calculation of real gas 
based on modified Benedict-Webb-Rubin equations. SPbPU Science Week: proceedings of a scientific conference with international participation. Institute of Energy and Transport Systems. - SPb .: Publishing house of the Polytechnic University, 2017 . 248 pp.

18. H. Krain, "A study on centrifugal impeller and diffuser flow,” Journal of Engineering for Power, vol. 103, no. 4, pp. 688-697, 1981 DOI: 10.1115/1.3230791.

19. Z. Guzović, M. Baburić, and D. Matijašević, "Comparison of flow characteristics of centrifugal compressors by numerical modelling of flow," Journal of Mechanical Engineering, vol. 51, no. 78, pp. 509-518, 2005.

20. B. E. Launder and D. B. Spalding, "The numerical computation of turbulent flows," Computer Methods in Applied Mechanics and Engineering, vol. 3, no. 2, pp. 269-289, 1974. DOI: 10.1016/0045-7825(74)90029-2

21. Ivanov, E.A., Zharkovsky, A.A., Borshchev, I.O., Svoboda, D.G. Technique for axial pump characteristics predicting in CFD package Openfoam. AIP Conference Proceedings v.2141,\#030063. (2019). DOI: 10.1063/1.5122113.

22. Zhurkin, N., Donskoj, A., Zharkovskij, A. Numeric modeling and estimating the performance characteristics of a pneumatic driven high pressure pump. (2018) MATEC Web of Conferences, 245, \# 09014. DOI: 10.1051/matecconf/201824509014.

23. Zharkovskii, A.A., Pospelov, A.Y. Use of 3D Methods for Flow Analysis, Prediction of Characteristics, and Optimization of the Shape of Settings of Hydraulic Turbines. (2015) Power Technology and Engineering, 49 (1), pp. 27-32.

24. Pospelov, A.Y., Zharkovskii, A.A. Effect of the Parameters of a Computational Model on the Prediction of Hydraulic Turbine Characteristics. (2015) Power Technology and Engineering, 49 (3), pp. 159-164. 